\title{
The European Federation of Organisations for Medical Physics. Policy Statement No. 12: The present status of Medical Physics Education and Training in Europe. New perspectives and EFOMP recommendations ${ }^{\text {is }}$
}

\author{
Teresa Eudaldo $^{\mathrm{a}, *}$, Kjeld Olsen ${ }^{\mathrm{b}}$
}

${ }^{a}$ Radiophysics and Radiation Protection Department, Hospital de la Santa Creu i Sant Pau, Avda. Sant Antoni $M^{a}$ Claret, 167, 08025 Barcelona, Spain

${ }^{\mathrm{b}}$ Department of Medical Physics, University Hospital Herlev, Denmark

Received 5 February 2009; received in revised form 26 February 2009; accepted 28 February 2009 Available online 9 April 2009

\section{KEYWORDS}

EFOMP;

Medical Physicists;

Education and training;

Continuous professional development

\begin{abstract}
A recently published EFOMP's survey on the status of Education and Training in Europe, has showed the important role played by the NMOs in the organisation of the Medical Physics education and training in most countries and their efforts to fulfil EFOMP recommendations. However, despite of this, there is still a wide variety of approaches within Europe, not only in the education and training programmes but also in professional practice.

There is right now some European issues that can affect not only education and training but also the future of Medical Physics as a profession: 1. the harmonisation of the architecture of the European Higher Education System, arising from the "Bologna Declaration", for 2010, 2. the recently issued European directive: "Directive 2005/36/EC of the European Parliament and of the Council of 7 September 2005 on the recognition of professional qualifications".

EFOMP is now challenged to make recommendations for education and training in Medical Physics, within the context of the current developments in the European Higher Education Area arising from "The Bologna Declaration", and with a view to facilitate the free movement of professionals within Europe, according to the new Directive.

( 2009 Associazione Italiana di Fisica Medica. Published by Elsevier Ltd. All rights reserved.
\end{abstract}

\footnotetext{
A Policy Statement issued jointly by the Education, Training and Professional Committee and the Standing Committee on Registration. Approved by EFOMP Officers in 2007 and by postal ballot in 2008. This manuscript is not subjected to peer review, being a Policy Statement of EFOMP.

* Corresponding author. Tel.: +34 9329193 16; fax: +34 932919276.

E-mail address: teudaldo@santpau.cat (T. Eudaldo).
} 


\section{Introduction}

Since its inauguration during the second conference of representatives from European organisations for Medical Physics in London in May 1980, one of the main objectives of the European Federation of Organisations for Medical Physics (EFOMP) has been to harmonise and promote the best practice of Medical Physics in Europe.

To achieve this goal, EFOMP has produced a number of unanimously adopted documents called "Policy Statements", making recommendations on the appropriate general responsibilities and roles of the Medical Physicist and proposing guidelines for Education, Training and Accreditation Programmes in Medical Physics. The most recent objectives of the EFOMP documents have been recommendations to implement Continuing Professional Development for Medical Physicists, and Guidelines on Professional Conduct. The total number of Policy Statements to date is 11 .

The first of these documents, Policy Statement No. 1 [1] was published at a very early stage, in 1984. It was entitled: "Medical Physics Education and Training: The present European level and recommendations for its future development", and it represents the starting point of the EFOMP recommendations on Education and Training in Medical Physics.

To produce the document, it was necessary to collect information about the current state of development of Education and Training in Medical Physics in each European country. For this purpose, two fact-finding inquiries were conducted, as a result of which 19 national organisations for Medical Physics described the current level of education and training in their individual countries.

The results of the inquiry provided a global view of the situation on Education and Training in Medical Physics at that time in Europe.

The first EFOMP recommendations on the schemes of Education and Training in Medical Physics and on the education programmes contents were based on these.

Today, more than twenty years later, the content of Policy Statement No. 1 is obviously obsolete. The organisation of the Medical Physics Education and Training in many countries has changed, and more recent EFOMP Policy Statements have been issued that have introduced new concepts and new recommendations that make thorough revision of this first document necessary.

For example, reference should be made to Policy statements No. 6 [2]: "Recommended Guidelines of National Registration Schemes for Medical Physicists", and Policy Statements No. 8 [3] and No. 10 [4] on Continuing Professional Development (CPD) for Medical Physicists. Also, in 1991 EFOMP, issued Policy Statement No. 4 [5] on the numbers of qualified physicists needed in a Medical Physics Department, and in the 1993, Policy Statement No. 5 [6] described the advantages, organisation and management of Departments of Medical Physics.

Furthermore, over the last two decades, the Council of the European Union has adopted new Directives on Medical Exposures and EFOMP has issued a series of relevant Policy Statements as a response to this new Legislation. In 1988 EFOMP issued Policy Statement No. 3 [7]: "Radiation Protection of the Patient in Europe: The training of the
Medical Physicist as a Qualified Expert in Radiophysics" which was the EFOMP response to the Directive 84/466/ Euratom [8]. In 1999, the Policy Statement No. 9 [9]: "Radiation Protection of the Patient in Europe: The Training of the Medical Physics Expert in Radiation Physics or Radiation Technology". This Policy Statement constitutes the EFOMP response to the Medical Exposure Directive, Council Directive 97/43/Euratom of 30 June 1997 on health protection of individuals against the dangers of ionising radiation in relation to medical exposure, and repealing Directive 84/466/Euratom [10].

Other important European issues that can affect not only education and training but also the future of Medical Physics as a profession are:

1. The harmonisation of the architecture of the European Higher Education System, arising from the "Bologna Declaration"' [11], for 2010.

2. The recently issued European directive: "Directive 2005/36/EC of the European Parliament and of the Council of 7 September 2005 on the recognition of professional qualifications"' [12]. This Directive establishes rules according to which "a Member State which makes access to or pursuit of a regulated profession in its territory contingent upon possession of specific professional qualifications shall recognise professional qualifications obtained in one or more other Member States and which allow the holder of the said qualifications to pursue the same profession there, for access to and pursuit of that profession".

EFOMP is now challenged to make recommendations for education and training in Medical Physics, within the context of the current developments in the European Higher Education Area arising from "The Bologna Declaration", and with a view to facilitate the free movement of professionals within Europe, according to the new Directive.

\section{The present status of education and training in Europe}

As previously stated, EFOMP has published the first Policy Statement (Policy Statement No. 1) [1] in a very early stage, in 1984, and it was entitled: "Medical Physics Education and Training: The present European level and recommendations for its future development".

This document provided a global view of the situation on Education and Training in Medical Physics at that time in Europe. The first EFOMP recommendations on the schemes of Education and Training in Medical Physics and on the education programmes contents were based on these.

To update this document, EFOMP decided to make a new survey on the status of Education and Training of Medical Physics in Europe. During 2005, a questionnaire was sent to 34 National Member Organisations (NMOs) for Medical Physics, to collect information on the present state of education and training in each European country. 25 countries provided relevant information by completing the questionnaire.

The results of this survey have recently been published [13] and were in agreement with the results of former 
EFOMP inquiries [14,15], on the occasion of the implementation of the EC Directives 97/43/Euratom (the "MED") [10] and 96/29/Euratom (the "BSS") [16] in Europe.

From these results, the important role played by the NMOs in the organisation of the Medical Physics Education and Training in most countries, and their efforts to fulfil EFOMP recommendations is highlighted. But, despite of this, there is still a wide variety of approaches within Europe, not only in the education and training programmes but also in professional practice.

\section{The new European perspectives}

\section{The higher education area by 2010: the Bologna Declaration}

In May 1998, the Ministers in charge of higher education in France, Italy, the United Kingdom and Germany signed the so-called Sorbonne Declaration on the "harmonisation of the architecture of the European Higher Education System" [11] at the Sorbonne University in Paris.

On 19 June 1999, 29 European Ministers in charge of higher education signed the Bologna Declaration on establishing the European Higher Education Area by 2010 and promoting the European System of higher education world-wide. In the Bologna Declaration [11], the Ministers affirmed their intention to engage in co-ordinating their policies to reach the following short-term objectives:

1. Adoption of a system of easily readable and comparable degrees (implementation of the Diploma Supplement)

2. Adoption of a system essentially based on two main cycles, undergraduate and graduate

3. Establishment of a system of credits, such as in the ECTS ${ }^{1}$ system.

4. Promotion of mobility

5. Promotion of European co-operation in quality assurance

6. Promotion of the necessary European dimensions in higher education

Subsequent documents issued from the Ministerial Conferences in Prague (19 June 2001) signed by 32 European countries, and in Berlin (19 September 2003) signed by 40 European countries, confirm the commitment to co-ordinating their policies through the Bologna Process to establish the European Higher Education Area [11]. In the last two conferences of European Ministers that have taken place in Bergen (19-20 May 2005) and in London (17-18 May 2007), six further countries have been welcomed as new participants. There are therefore 46 European countries presently involved in the "Bologna Process".

\footnotetext{
${ }^{1}$ European Credit Transfer System is a student-centred system based on the student workload required to achieve the objectives of a programme of study. These objectives should preferably be specified in terms of learning outcomes and competencies to be acquired. ECTS is based on the principle that 60 credits measure the workload of a full-time student during one academic year. ECTS makes study programmes easy to read and compare. It can be used for all types of programmes, whatever their mode of delivery, and for lifelong learning purposes.
}

According to the EFOMP recommendations given in the EFOMP Policy Statement N.1, education of medical physicists can be divided into three stages.

The first is to bring the physicist up to a basic standard during an initial period of training at the university in physics, mathematics and other relevant topics in natural science. The second is to introduce medical physics in the post-graduate education and the third is in-service training in hospitals. Once completed, the physicist can be recognised as a medical physicist.

The "Bologna Process" offers a great opportunity to harmonise the first two stages of education in the participating countries:

- The first step should correspond to the initial university cycle; the degree in physics or other scientific areas will be more transparent and equivalent throughout Europe as of 2010. (Lasting 3 years minimum or 4 years, so 180-240 ECTS.)

- The second step should correspond to a second university cycle leading to a master's degree. (1 or 2 years and up to 300 ECTS.)

- The third step is in-service training in hospitals. This inservice training period should consist of at least two years, under the supervision of an experienced Medical Physicist.

Only after completion of these three periods, can the Medical Physicist be considered competent to act independently, and reaching the minimum qualifications required for enrolment in an EFOMP-approved National Register [2] for Medical Physicists as a Qualified Medical Physicist [4].

\section{Recognition of professional qualification: directive 2005/36/EC}

The recently issued EU document: "Directive 2005/36/EC of the European Parliament and of the Council of 7 September 2005 on the recognition of professional qualifications" [12] and published in the Official Journal of the European Union on 30-09-2005, defines (Title I, Article 3):

(a) 'regulated profession': a professional activity or group of professional activities, access to which, the pursuit of which, or one of the modes of pursuit of which is subject, directly or indirectly, by virtue of legislative, regulatory or administrative provisions to the possession of specific professional qualifications; in particular, the use of a professional title limited by legislative, regulatory or administrative provisions to holders of a given professional qualification shall constitute a mode of pursuit.

Later, Article 21, defines the principle of automatic recognition on the basis of co-ordination of minimum training conditions. A set of health-care professions, as well as architects, has an automatic recognition through the EU member states, solely based on the co-ordination of minimum training conditions.

In the context of this new Directive, EFOMP aims to achieve recognition of Medical Physics as a regulated 
health-care profession on the basis of co-ordination of minimum training conditions. This will guarantee the best uniformity of knowledge and skills and will facilitate the free movement of professionals within Europe.

The responsibilities of Medical Physicists working in a hospital environment in the areas of diagnosis and treatment of patients do not differ much from those of other health-care professionals.

Therefore, EFOMP strongly supports Medical Physics being considered as a health-care profession.

\section{EFOMP recommendations in view to these new European challenges}

1. EFOMP strongly encourage NMOs to strive to make a university Master Degree in Medical Physics available at their universities. This master should include the theoretical curriculum contents recommended by EFOMP in their Policy Statements $[1,7,9]$ and in other documents that EFOMP has produced in collaboration with other relevant societies $[17,18]$.

2. From EFOMP's point of view, holding a university Master Degree in Medical Physics, is not a sufficient qualification to work as a Medical Physicist in a hospital environment. To manage patients without supervision, EFOMP recommends a second part in the post-graduate training: at least 2 years' training experience on-thejob. Only after completion of this training can a physicist be considered a Medical Physicist and able to work independently as a Qualified Medical Physicist (QMP) [4]. The on-the-job training is essential to achieve the competencies to work as QMP.

3. EFOMP recognises and values the important role that NMOs have played until now in setting up and managing the education and training programmes for Medical Physicists in most countries. In the future, EFOMP recommends that the NMOs efforts be aimed at involving Health Authorities in the education and training programmes in order to obtain official recognition as a health profession. EFOMP considers it an essential requirement that the Ministry of Health or National Health Authorities be involved in the recognition/accreditation of the post-graduate training (mainly the second part: "on-the-job training").

4. EFOMP strongly encourages NMOs to set up a formal CPD programme for Medical Physicists, credit point based, according to EFOMP recommendations. Medical Physicists enrolled in a CPD programme can become Specialist Medical Physicists (SMP) [4] by gaining advanced clinical experience and undergoing specialist training, mostly in one sub-speciality. In Policy Statement No. 10 the duration of this experience and training was stated as a minimum of 2 years. The duration of a full CPD cycle is 5 years. EFOMP recommends that the minimum of two years should only be used for an interim period. With the rapid increase in complexity of diagnostic and therapeutic procedures and equipment the full length of five years advanced clinical experience and specialist training should be used to become accepted as Specialist Medical Physicist.

5. The official registers of professionals managed by the authorities are usually very static and renewal mechanisms are usually not planned. EFOMP therefore recommends that NMOs start their own register of professionals, managed by their own registration board, and including some CPD-based renewal mechanism.

Fig. 1 summarizes EFOMP recommendations on Education and Training.

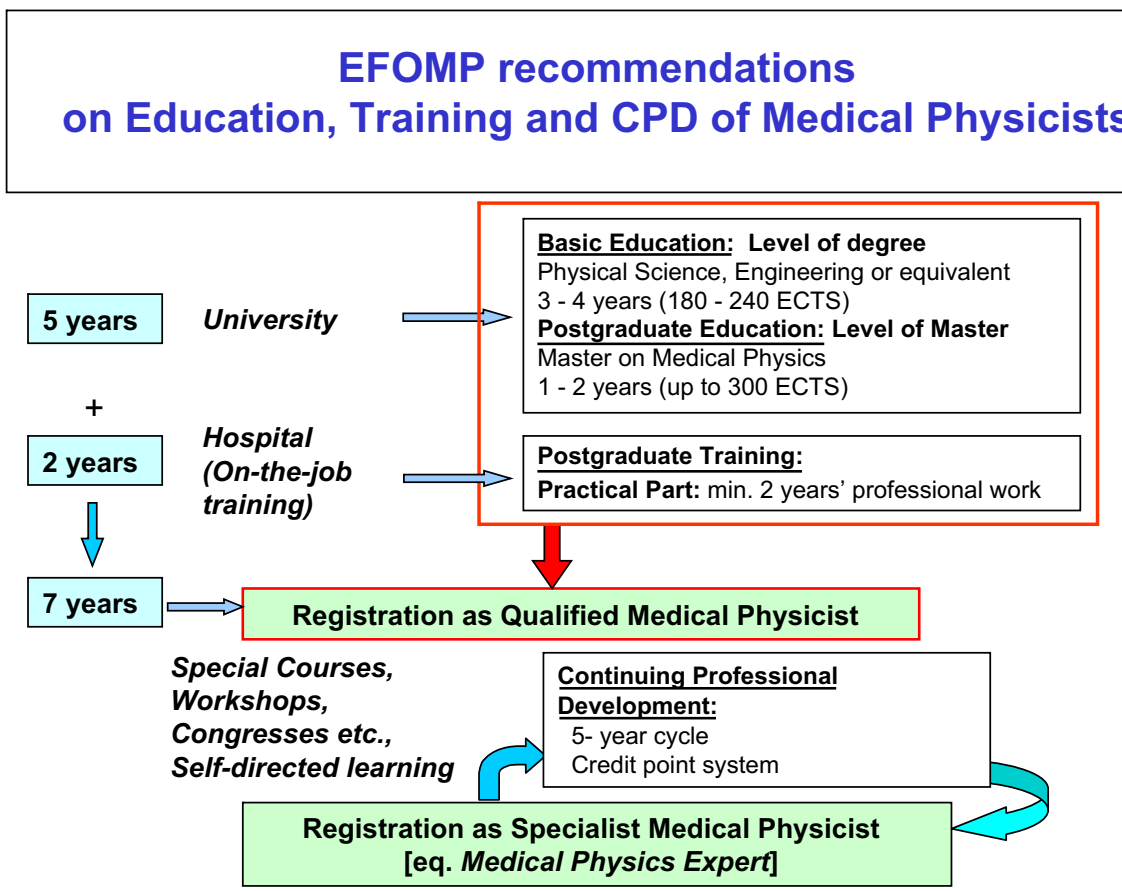

Figure 1 EFOMP recommendations on Education and Training and CPD of Medical Physicists. 


\section{Acknowledgments}

The authors acknowledge all EFOMP's Officers who have always supported the initiative and have contributed to the final version of this document with comments, suggestions and even grammar corrections.

\section{References}

[1] EFOMP Policy Statement No. 1. Medical physics education and training: the present European level and recommendations for its future development. Available from: http://www.efomp. org; 1984.

[2] EFOMP Policy Statement No. 6. Recommended guidelines of national registration schemes for medical physicists. Physica Medica 1995; XI(4):157-9.

[3] EFOMP Policy Statement No. 8. Continuing professional development for the medical physicist. Physica Medica 1998; XIV (2):81-3.

[4] EFOMP Policy Statement No. 10. Recommended guidelines on national schemes for continuing professional development of medical physicists. Physica Medica 2001;XVII(2): 97-101.

[5] EFOMP Policy Statement No. 4. Criteria for the number of physicists in a medical physics department. Available from: http: //www.efomp.org; 1991.

[6] EFOMP Policy Statement No. 5. Departments of medical physics - advantages, organisation and management. Available from: http://www.efomp.org; 1993.

[7] EFOMP Policy Statement No. 3. Radiation protection of the patient in Europe: the training of the medical physicist as a qualified expert in radiophysics. Available from: http:// www.efomp.org; 1988.

[8] Directive 84/466/Euratom of 3 September 1984 on the basic measures for the radiation protection of persons undergoing medical examination or treatment. Official Journal of the European Communities 5 October 1984:1. No. L 265.

[9] EFOMP Policy Statement No. 9. Radiation protection of the patient in europe: the training of the medical physics expert in radiation physics or radiation technology. Physica Medica 1999;XV(3):149-53.

[10] Directive $97 / 43 /$ Euratom of 30 June 1997 on health protection of individuals against the dangers of ionising radiation in relation to medical exposure. Official Journal of the European Communities 9 July 1977:22. No. L 190.

[11] Available from: http://ec.europa.eu/education/policies/ educ/bologna/bologna_en.html.

[12] Directive 2005/36/EC of the European Parliament and of the Council of 7 September 2005 on the recognition of professional qualifications. Official Journal of the European Communities 30 September 2005:22. No. L 255.

[13] Eudaldo T, Olsen K. The present status of medical physics education and training in Europe: an EFOMP survey. Physica Medica 2008;24(1):3-20.

[14] Van Kleffens HJ. Actual situation of implementation of ECDirective 97/43/Euratom [MED] in Europe. Physica Medica 2000;XVI(3):165-7.

[15] Van Kleffens HJ. Implementation of the EC-Directives 97/43/Euratom [MED] and 96/29/Euratom [BSS] in Europe. Physica Medica 2002;XVIII(4):149-52.

[16] Directive 96/29/Euratom of 13 May 1996 laying down basic safety standards for the health protection of the general public and workers against the dangers of ionising radiation. Official Journal of the European Communities 29 June 1996:1. No. L 159.

[17] Eudaldo,T, Huizenga H, Lamm IL, et al. Guidelines for education and training of medical physicists in radiotherapy. Recommendations from an ESTRO/EFOMP working group. Radiotherapy and Oncology 2004;70:125-35.

[18] European Commission, Radiation Protection 116. Guidelines on education and training in radiation protection for medical exposures. Luxembourg: Directorate General Environment, Nuclear Safety and Civil Protection; 2000. 